\title{
7. The agenda for achieving a world- class public sector: making reforms that matter in the face of challenges
}

\author{
Stephen Sedgwick
}

This chapter begins by discussing some key issues surrounding public-sector reform. It will then explore public-sector change at the national level in Australia since the modern reform era began in the mid 1970s, and the implications for us today. My primary focus will be directed towards the comprehensive reform program set out in the landmark publication Ahead of the Game: Blueprint for the reform of Australian government administration (Moran 2010), which is in the process of being implemented, subject to the policy priorities of the Gillard government. ${ }^{1}$ The chapter will conclude with some thoughts about what tomorrow might bring and how we can continue to work towards having a world-class public sector and maintain the momentum needed to support sustainable change.

\section{Public-sector reform in theory and practice}

Reform is essentially about balancing continuity and change, choosing between incremental change and more substantial change. As the management thinker Charles Lindblom put it, 'incremental reformers' are concerned primarily with marginal improvements that they can agree on in practice, whereas critics of incrementalism are concerned with a more systematic approach to setting objectives and achieving measurable outcomes (Lindblom 1959:79-88, 1979:517-26). Lindblom identified this dichotomy and the implications of each approach more than 50 years ago, but it still has resonance today. The challenge for reformers is judging when fundamental, rather than incremental, change is required.

In a recent publication, the Organisation for Economic Cooperation and Development (OECD 2010:27-8) identified five generic lessons to emerge from a study of global public-sector reform initiatives

\footnotetext{
1 In September 2009, the then Prime Minister, Kevin Rudd, appointed an Advisory Group chaired by the head of his department to develop a blueprint for major reform of the Australian Public Service (APS). The Advisory Group's report, entitled Ahead of the Game (Moran 2010), contained 28 recommendations across four themes. The current government has accepted all of them.
} 
1. the importance of raising citizen awareness of, and support for, reform through public debates and consultation strategies

2. the need to consult extensively with public servants affected by reform

3. the requirement to reduce uncertainty, and therefore opposition to reform, by allowing it to proceed in stages - that is, 'incrementally'

4. the need for permanent, independent organisations for steering reform, especially after the initial stages in order to prevent incrementalism giving way to inertia and reform stalling

5. the importance of individual national jurisdictions supporting and collaborating with international public-sector research organisations in information sharing and evaluating reform approaches and progress.

All of these elements are to be found in previous reforms to the Australian Public Service (APS), but it is fair to say they certainly figure prominently in current thinking and initiatives and no doubt will continue to loom large in future. There is another important aspect to designing sustainable or fit-for-purpose reform approaches: the little-explored conception of a nation's 'administrative tradition' (Painter and Peters 2010). A sound understanding of the influence of a country's administrative tradition is needed in framing sustainable reform initiatives and charting their progress.

\section{Exploring the key issues in Australian public- sector reform, 1976-2010}

During the past four decades, successive Australian governments and the public sector have been called on to address the challenges of a rapidly changing world. They have done so by revising existing policies and programs and developing new ones. Public service leaders have sought to learn from past initiatives when framing new reform proposals. The outcomes of the recent review of the APS reflect elements of continuity and change with key themes from earlier publicsector reforms as far back as the 1970s. Successive generations of public servants are constantly called upon to adjust their thinking and practices to respond to the changing needs and expectations of their communities and to exploit new options to solve problems as technology (including administrative technology) changes.

Let us explore these issues by looking at the evolution over time of three major themes. The first concerns the public sector's stewardship role; the second, its success in centralising or decentralising its various functions and the effect this has on its operations; and the third, the effectiveness of the APS accountability framework. In each case, I will focus principally on the human-resources components of the reforms. 
Two pieces of major legislation - the Public Service Reform Act 1984 and the Public Service Act 1999-and the findings of a number of inquiries and task forces attest to the determination of successive governments to create an efficient and effective APS. The most recent of these is, of course, Ahead of the Game (Moran 2010), a far-reaching blueprint for the reform of Australian government administration, released in March 2010 and formally approved in May.

In examining the three key themes outlined above, I will be looking at this legislation and these inquiries as carefully considered responses to new demands on the public sector. It must be said, however, that we have been more successful in some areas than in others. The process is always one of learning and adaptation, of reconciling continuity and change, of managing expectations and making the best use of the available resources.

No single reform approach ever has all the answers - partly because our external environment is never static and neither should the public service be static; and partly because the balance between centralisation and decentralisation shifts over time as technology changes. Our most recent reforms - some of which have moved us back a little compared with earlier initiatives - are best viewed in that light.

Several forces have shaped public-sector change over the past four decades - a period marked by what one commentator calls 'a major re-conceptualisation of the role of government' (Nethercote 2003:12). The main influences have been

- new service-delivery opportunities, cost-saving opportunities and accountability demands created by advances in information and communications technology

- globalisation

- a more contestable policy formulation and service-delivery environment

- increasing community expectations of government-not just for highquality services and efficient regulation, but also a palpable sense that 'government' should be able to solve almost any problem, no matter how complex it might seem, or how intractable it had appeared in the pastand growing intolerance of poor performance whether in direct provision of services or through regulation.

This has led to what has been called a 'reinvention of government' - one characterised by a more agile and flexible approach to public policy and a high level of responsiveness to society's needs (Albrow 2001:158, 162). 


\section{The stewardship role and the need to be Ahead of the Game}

The findings of the Royal Commission on Australian Government Administration, known as the Coombs Inquiry, are well known. The Coombs Inquiry, which reported in 1976 (Coombs 1976), was the first large-scale inquiry into the Public Service since the 1920s (McLachlan 1920). ${ }^{2}$ It took two years to complete and called on the APS to

- increase its responsiveness to the elected government

- improve its efficiency and effectiveness

- foster greater community participation in government.

Indeed, these themes have been reflected in successive APS review and reform processes since the Coombs Report was released in 1976-an important element of continuity in our reform process.

Coombs called for, amongst other things, stronger policy coordination across government through the Department of the Prime Minister and Cabinet and more positive steps designed to enhance the flow of information to the community. There were concerns at the time that departments were operating too independently of each other and possibly of government and that the APS was less responsive to the government of the day and their interpretation of changing community needs than it should be.

These themes were developed and enshrined in the Public Service Reform Act 1984, which stipulated that a portfolio secretary should exercise their responsibilities for the general operations of his or her department under a greater degree of ministerial direction than in the past. This emphasis was taken further in the Public Service Act 1999, which gave portfolio secretaries considerably more flexibility in administering their organisations and serving the public, but with greater accountability for results.

The key point for our analysis here is that by 2010 questions were being raised about whether our understanding of the role of the senior leaders of the Public Service had become too narrow over time. Compared with Coombs' times, now there is a strongly embedded acceptance that the APS must be responsive to the government of the day, and manage risk and deliver results for citizens (and not simply comply with processes). All of these were matters that, in Coombs' time, were in need of repair.

2 McLachlan was a retired Public Service Commissioner. 
While not losing sight of those essential qualities of public service, some had begun to shift their attention to another question-namely, whether public service thinking had become too reactive, too government centred and too short term. This sparked a debate about what historically has been termed the 'stewardship role' of senior public servants. This role requires public servants to be more proactive and forward thinking - both in their management of the APS workforce and in their development of policy thinking and models of service delivery. Some of this is about the responsibilities of today's leaders to build the capability needed within the APS to respond to tomorrow's problems; some relates to the importance that should be attached to having strategic policyadvising capability within departments to advise governments about what the policy issues and approaches should be.

The domestic and international environments in which nations now operate present political and public-sector leaders with a number of pressing challenges. These have become known as 'wicked problems' and include, in our case, nationwide water shortages occasioned by an unusually long drought; concern about some seemingly intractable, multifaceted social issues such as Indigenous disadvantage, homelessness and mental health; and growing international attention to 'diabolical problems' (to use Ross Garnaut's term) such as global climate change and security challenges, including those related to several largescale terrorist attacks on a number of continents.

The recent Ahead of the Game report (Moran 2010) picked up these themes. It set out a comprehensive change strategy for the APS, which, first and foremost, reemphasised that the needs and requirements of citizens have to be at the centre of policy design, service design and delivery; it also challenged the Public Service to be more forward looking. The report called on the senior leaders of the APS to look again at how programs are designed and delivered to ensure that they meet the needs of citizens in ways that are convenient for them rather than for public servants, and to minimise regulatory burdens. These require more 'joined up' approaches to government and a re-examination of how we hold agencies accountable for results that need several of them to work together. Some of these proposals challenge our traditional accountability models, which I will discuss below.

Ahead of the Game placed specific responsibility on a new public service leadership forum - a Secretaries Board - to find better ways of joining up government services and articulating an accountability framework that reflected contemporary understanding of how government needs to interact with citizens. It will also involve strengthening the capacity of the APS to provide strategic, big-picture advice that addresses the most difficult challenges of the day, among them the capacity to identify fundamental rather than incremental change 
when the situation requires it. Agencies have been challenged to assess their capability in these matters and to systematically set about building capability if they are currently deficient.

The performance of agencies and individuals should be assessed in a number of ways, notably through the introduction of systematic capability reviews that will be conducted centrally using teams and approaches to be developed by the Australian Public Service Commission (APSC). Importantly, Ahead of the Game put renewed emphasis on the fact that the APS is a long-lived institution with responsibilities to the future and not just the present; that the APS workforce needs to be resilient in the face of the unexpected, and to develop policymaking capability ahead of predictable need - in other words, to look towards tomorrow and see what issues might emerge in future that we should begin to research today, ahead of need.

The new Secretaries Board, comprising portfolio secretaries and the Public Service Commissioner, along with an expanded senior leadership forum (the APS 200) will be central in driving the stewardship function. For example, a small group has been formed from within the APS 200 to take forward the APS capability and service-delivery improvement agenda set out in the Management Advisory Committee report Empowering Change: Fostering innovation in the Australian Public Service, released in May. Along with its responsibilities to identify better ways to 'join up' government for citizens, the board also has responsibilities to oversee the development of the APS workforce, including through more centralised approaches to leadership training and talent management.

The APS blueprint will have far-reaching consequences for Australians and public servants. It represents a recognition that many traditional approaches to public policy no longer work as consistently well as they once did. Consequently, governments and public servants increasingly have to review and, as necessary, refresh their models of policy formulation and service delivery in response to the expectations of citizens. And APS leaders cannot perform this role well without managing their organisations in order to ensure that they are adaptive, self-critical, outward oriented - that is, especially citizen focused-and forward thinking. Ahead of the Game sets out how they can go about this internally and in their relations with citizens. 


\section{Striking a balance in centralisation and decentralisation}

The 1976 Coombs Inquiry reaffirmed the need for centralised oversight of public-sector employment legislation by the then Public Service Board, the body responsible at the time for the APS industrial-relations and human-resources functions (and a predecessor of the APSC). In the interests of achieving a more open but better integrated public service, Coombs, however, called for the creation of a separate cadre of APS senior executives and the beginnings of devolution from the centre - more specifically, from the Public Service Boardof greater responsibility for agency operations to agency heads.

This began a process of devolution of human-resources management that played out over many years and culminated in the abolition of the Public Service Board in the late 1980s and the introduction of the current Public Service Act in the late 1990s. The board was replaced with a Public Service Commission with a relatively limited role. It was responsible for developing the Senior Executive Service and training, consulting and advising government on public-sector change, and some human-resource systems and human-capability alignment functions such as recruitment, promotion, dismissal, mobility and retirement matters. Under the provisions of the Public Service Act 1999, agency heads were given all the powers of employers over staff, subject to a new ethics framework enshrined in the Act in the form of legally enforceable APS Values and a Code of Conduct.

Parallel reforms had occurred in respect of financial management so that agency heads and their senior managers were now provided with full responsibility for reconciling their organisation's budgetary, performance and accountability, and risk-management priorities with those relating to recruitment, training, employee development and leadership. Eventually, agency heads also received power to determine pay and conditions within their agency, subject to only light central oversight.

Some centralised elements remained, however. In the case of human-resources management, the APSC's role, for example, was to be one of promoting and reviewing APS employment policies and practices across the Public Service, as well as quality assurance in the areas of people management, training and career development, and leadership. The essential point is that these centralised elements were very light handed. The commission was to promote and encourage good practice but had limited authority or leverage to enforce compliance. 
Again, the 2010 reform blueprint recommended a subtle change of direction. It proposed an amalgam of past, existing and new approaches to the challenges we face, many of which call for more innovative thinking. In the human-capital area, for example, Ahead of the Game moved beyond 'people management' as we have traditionally defined it to a more holistic philosophical approach, which recognises that the short and longer-term capabilities of our organisations need to be planned for and systematically developed.

This reflects a realisation that good people management underpins an effective human-capital strategy, which in turn underpins the capacity of the APS to achieve its strategic objectives and meet the evolving demands of citizens. It also proposes, in essence, a degree of re-centralisation - but not of the same order as we knew in the past. It proposes that agency heads retain all the powers of an employer, but that these powers should be exercised within a more consistent, centrally determined and monitored framework. The commission will have more and stronger levers to promote good practice and to expose poor practice.

Current government policy is that greater consistency will be reflected, for example, in new arrangements for better aligning pay and conditions across agencies and, on efficiency grounds, in a continuation of the trend towards more centralised information and communication technology (ICT) management. Moreover, Ahead of the Game requires the APSC, for instance, to

- establish APS-wide frameworks for human-capital management, including in respect of workforce planning

- simplify APS recruitment processes so as to attract the best applicants from the public and private sectors

- revise the legislated APS Values to a smaller set better able to influence workplace behaviour

- revise the APS's performance-management frameworks to ensure not only that poor performance is identified and managed but, for the first time, that high-potential individuals are systematically identified and their development accelerated

- establish a Strategic Centre for Leadership, Learning and Development to achieve stronger strategic alignment between the commission's leadership development and talent-management activities and contemporary humancapital priorities of the APS

- undertake human-capital benchmarking, capability reviews and a citizens' survey.

A Human Capital Priority Plan is to be developed for consideration by the Secretaries Board to assist in implementing these initiatives and, over time, identify emerging systemic workforce issues for the APS at large. Additionally, 
the longstanding emphasis on APS-wide, whole-of-government collaboration as a means of generating optimal outcomes will be strengthened. These reforms challenge the Public Service to adopt a more systematic and consistent approach to workforce planning and to developing its people. At the moment only 30 per cent of agencies undertake systematic workforce planning and only 8 per cent actively engages in talent-management activities. More consistent approaches are to be developed and promulgated, and performance routinely assessed and supported by the commission. The aim here is to avoid both excessive interference from the centre and the development of a compliance or 'tick box' mentality in agencies.

The important element of this reform is to provoke debate within agencies and at the level of the Secretaries Board about the needs of the APS workforce, and to embed active management of the workforce into agency practices by concentrating on strategically relevant issues that add value to an agency's management. These issues will need to be established and periodically updated through dialogue with agencies and their leadership. A central element in this process will be to build a workforce that reflects the diversity of the population whose needs the APS seeks to anticipate and serve. In a couple of critical areasespecially in respect of the representation of Indigenous Australians, those with a disability or, at senior levels, women - the APS certainly has room to improve. Improved performance and talent-management processes will be put in place; clearer work-level standards designed to enable better alignment of skills and training to job requirements are to be introduced; and salaries and conditions will be better aligned.

It must also be noted that there has been a degree of re-centralisation over time in respect of some financial-management functions. But these changes have essentially responded to new opportunities presented to exploit economies of scale using centralised purchasing - for example, in respect of travel - or common services or ICT. The fundamental thrust to devolution of financial management, the flexibility of agencies to reallocate resources and the use of program budgeting remain unchanged.

\section{Effective accountability: from the Financial Management Improvement Program to horizontal coordination and performance assessment}

If we look back once more to the Coombs Inquiry, it called for greater agency accountability by means of a strengthened annual reporting process for departments. Coombs also advocated a higher level of accountability for individual public servants. An ambitious initiative designed to improve 
departmental financial management - a recommendation of the 1983 Review of Commonwealth Administration-also occurred at this time, with the establishment in 1984 of the Financial Management Improvement Program. It encompassed a broad range of change initiatives in the areas of corporate and program management, program budgeting, and performance evaluation. These reforms were designed to improve strategic planning and policy formulation and to ensure the more efficient use of resources. They were to be realised through better framing of goals and objectives and improved management and measurement for results and outcomes.

A central theme of the Public Service Act 1999 was that public administration, including systems and human-capability alignment functions, would be improved by strengthening the accountability - and integrity - of government. This was in part a response to the increased availability of online data that could be used to make judgments about public-sector performance. The Ahead of the Game report took the accountability issue a step further. It proposed that secretaries devise a coordinated response to develop more variegated accountability and performance arrangements better suited to the new modes of policy implementation and service delivery that the APS must increasingly deploy. Initially, this calls for an accountability model that will ensure effective oversight, without stifling innovation and preferably while also reducing the web of unnecessary rules that saps employee initiative. Some of these rules are devised within agencies and seem to add no value. But it goes further than that.

A major challenge for a citizen-centric service is to present a more joined-up face to citizens - one that respects the convenience of the users rather than the providers of services. There are many aspects to this issue. For example, traditionally we have defined accountability through a single minister and the public servants who deliver a specific program on his or her behalf. But some problems cannot be addressed through a single program or minister, such as Indigenous disadvantage in remote localities. Better outcomes for these Indigenous Australians require improvements in health, housing and schooling, amongst other things, that are mutually reinforcing. Yet, traditionally we have assessed these programs separately, and no-one has accepted responsibility for the overall outcome - failure to advance the life chances of these Indigenous peoples has been seen as someone else's problem; in effect, they have fallen between the cracks in our accountability framework. The fact that responsibility for some of these issues is shared across several levels of government in a federal structure simply compounds the degree of difficulty.

The new reform agenda challenges the Public Service's leadership to work systematically through our service-delivery models and accountability frameworks to find solutions to how we can better hold agencies and individuals accountable for their contribution to achieving desired outcomes when a 
number of programs, portfolios or jurisdictions are involved. In parallel with this, the APS intends to establish more robust and effective risk-management systems, as well as new monitoring and reporting arrangements. These include an improved performance-assessment framework for secretaries - one that is to involve a higher level of feedback from their peers and subordinates as well as stakeholders. Ahead of the Game proposed that feedback should be sought about all of the roles that agency heads are to perform, including their stewardship responsibilities, their management of their department and outcomes achieved, and the quality of their policy advice. Moreover, the APSC has also been given a formal role in monitoring and reporting on the implementation of all Ahead of the Game recommendations. Together with the introduction of human-capital benchmarking, capability reviews and the citizens' survey, these represent a significant increase in the leverage available to the APSC in effecting change.

\section{Delivering reform: reflections to date and into the future}

Today's reform agenda is the latest manifestation of the reform imperative whereby policies and practices are redefined in response to a changing national and international governance environment. Three specific developments have been significant in changing the environment in which the APS functions

1. improvements in civic participation as a result of increasing education levels, leading to more specific citizen expectations of government

2. continual economic pressures and the need to produce better outcomes with fewer resources

3. Australia's ageing population and workforce (including the APS workforce).

Moreover, our challenges are more numerous and their nature more complex than in the past, leading us to rethink how the Public Service can work better internally and engage externally with citizens and with the best contemporary thinkers to find solutions. What lessons have we learnt from four decades of reform?

APS leaders must be clear about their objectives and ensure that the effort they are expending remains commensurate with the benefits they expect to generate. Sound reform should be defined as the delivery of sustainable change over time. This change is as much about human capability and alignment as it is about administrative change; it is about achieving the right balance between systems and people; and it is about balancing the needs of the present and the future (including stewardship obligations), centralisation and decentralisation 
of functions. I also believe that incentives and the accountability framework matter. Effective change requires behavioural changes. This requires good communication of the case for change and the nature of what is expected; however, in addition, the incentives structures and the accountability regimes have to be aligned with the objectives of the reforms. And, as we all know, in applying incentives and administering accountability, what the regulators and public service leaders do is more important than what they say-their actions will drive an organisation's culture and its approach to the acceptable standards of work, values and focus on clients.

It is also important to recognise that the various elements of a specific reform process need not be undertaken or completed all at once; establishing priorities for change and realistic time frames is a significant component of sound reform. In the tradition of our predecessors, we should continue to enrich reform approaches through self-critical evaluation, research and knowledge of international best practice - in short, with evidence; and, as Ahead of the Game advocates, do this by forging better links with public administration research and training institutions such as ANZSOG as well as other think tanks. This applies to all aspects of public-policy activity.

Ahead of the Game has rightly drawn on recent developments in the United Kingdom, Canada and New Zealand to adapt and borrow new techniques to foster accountability and improve links with citizens and others to achieve better outcomes. The citizens' survey and capability reviews are examples of this. But it has also learnt from our experience with past reform about the need to get the balance right between immediate needs and longer-term ones, and between too loose and too tight approaches to devolution of authority to act. These are reflected in the heightened attention to be paid to the stewardship responsibilities of secretaries and the stronger emphasis on approaches in the blueprint to managing human capital that acknowledge that we are 'One APS' (Management Advisory Committee 2005) united by common values and expectations of performance.

A further reflection is that reform is about people - their motivations, the incentives they face, their flexibility and willingness to change. It is about focusing and refocusing on factors such as employee engagement. Kenneth W. Thomas, for example, has identified four central elements in what he terms 'intrinsic motivation': a refinement of the traditional conception of engagement, and one that produces better organisational outcomes. It does so primarily because the greater autonomy employees often enjoy compared with in the past allows those with a high level of intrinsic motivation to perform very effectively. These elements are: a sense of meaningfulness; a sense of choice; a sense of competence; and a sense of progress (Thomas 2009). In the APS context, we professionalised our financial-management processes long ago but so far 
have not achieved the same degree of professionalisation of our human-capital approaches - perhaps because they are too difficult to quantify and therefore address.

And the final observation based on our experience since the 1970s is the central importance of good leadership; this imperative recurs in review after review. In each generation, we need to develop leaders who embody the best values of public service; who look outward to identify the needs of those whom we serve; who look forward to anticipate emerging issues and build resilient organisations; who are not afraid to take on the tough issues; who are accountable; who know how to communicate and manage change; and who are prepared to respond to and seek to influence the agenda of the government of the day. Building such a leadership cadre is a fundamental precondition for sustained reform and high performance.

\section{Conclusions: reform as invention and reinvention}

The reform initiatives undertaken by successive Australian governments and the public sector since the mid 1970s attest to their desire to better serve Australians through more flexible and agile responses to changing national and global imperatives. They also demonstrate that, as Australia's place in the world changed and we were called upon increasingly to function in a globalised social, economic, governmental and public-sector environment, we learned to develop more agile and responsive approaches to meeting the needs of governments and citizens. This imperative remains - perhaps to a greater extent than in the past. According to one commentator, the most critical question for every twentyfirst-century organisation is this: 'are we changing as fast as the world around us?' (Hamel with Breen 2007:42).

Highly functional public-sector organisations that effectively align their human-capital and structural arrangements stand the best chance of successful adaptation. Such organisations will also be efficient stewards of their resources, adept at achieving the right balance between centralisation and decentralisation of their functions, and guarantors of effective accountability. They will maintain their capability only if they address internal challenges such as those associated with the growing 'virtual' workplace - for example, the pressures on workers such as isolation arising from tele-working (already a trend in the United States). And we can fulfil our role effectively only by keeping a close eye on how society is changing and by equipping ourselves to deal with societal change. I am certain that we never can get to a final point - there is always room for improvement in what we do now, and the reform process itself is essentially a matter of invention and reinvention. 
Charles Lindblom in "The science of "muddling through"' declared that incrementalism as an approach to public administration did not lack rigour; it represented a legitimate and considered response to addressing challenges and delivering outcomes in the actual forest of events public-sector managers face daily. Twenty years on, he had not changed his mind, writing that we were 'Still muddling, not yet through' (Lindblom 1959:79-88, 1979:517-26). As Lindblom recognised, the enterprise is not about conquering but about persevering, continual adaptation and change. And therein lies the challengeand the excitement - of being a career public servant.

\section{References}

Albrow, M. 2001, 'Society as social diversity: the challenge for governance in the global age', in Governance in the 21st Century, Organisation for Economic Cooperation and Development, Paris.

Coombs, H. C. (Chairman) 1976, Royal Commission on Australian Government Administration Report, AGPS, Canberra.

Hamel, G. with Breen, B. 2007, The Future of Management, Harvard Business School Press, Boston, Mass.

Lindblom, C. E. 1959, 'The science of "muddling through"' , Public Administration Review, vol. 19, no. 2 (Spring), pp. 79-88.

Lindblom, C. E. 1979, 'Still muddling, not yet through', Public Administration Review, vol. 39, no. 6 (November-December), pp. 517-26.

McLachlan, D. C. (Chairman) 1920, Royal Commission on Public Service Administration Report, Government Printer, Melbourne.

Management Advisory Committee 2005, One APS-One SES: Senior Executive Service of the Australian Public Service, Australian Public Service Commission, Canberra, <http://www.apsc.gov.au>

Management Advisory Committee 2010, Empowering Change: Fostering innovation in the Australian Public Service, May, Australian Public Service Commission, Canberra.

Moran, T. (Chairman) 2010, Ahead of the Game: Blueprint for the reform of Australian government administration, Advisory Group on Reform of Australian Government Administration, Department of Prime Minister and Cabinet, Canberra. 
Nethercote, J. R. 2003, 'Australian public administration in perspective', in Australian Public Service Commission, The Australian Experience of Public Sector Reform, Commonwealth of Australia, Canberra.

Organisation for Economic Cooperation and Development (OECD) 2010, Making Reform Happen: Lessons from OECD countries, Organisation for Economic Cooperation and Development, Paris.

Painter, M. and Peters, B. G. (eds) 2010, Tradition and Public Administration, Palgrave Macmillan, Houndmills, Basingstoke, UK.

Thomas, K. W. 2009, Intrinsic Motivation at Work: What really drives employee engagement, (Second edition), Berrett-Koehler Publishers, San Francisco. 